\title{
Continuous and Sustainable Cellulose Filaments from Ionic Liquid Dissolved Paper
}

\section{Sludge Nanofibres}

\section{Cynthia Adu ${ }^{\mathrm{a}}$, Chenchen Zhu ${ }^{\mathrm{b}}$, Mark Jolly ${ }^{\mathrm{a}}$, Robert M. Richardson ${ }^{\mathrm{c}}$, Stephen J Eichhorn ${ }^{\mathrm{b}}$}

aSustainable Manufacturing Systems Centre, Cranfield University, Cranfield, Bedfordshire MK43 0AL, United Kingdom

${ }^{b}$ Bristol Composites Institute, School of Civil, Aerospace, and Mechanical Engineering, University of Bristol, Bristol BS8 1TR, United Kingdom

'HH Wills Physics Laboratory, Physics Department, University of Bristol, Tyndall Avenue, Bristol BS8 1TL, U.K.

\begin{abstract}
The textile industry is resource intensive, which has a significant impact on global emissions and waste pollution. To meet the demand of textiles over a third of fibres used in manufacturing are sourced from fossil fuels. As the global demand for textiles continues to grow, manufacturers have having to seek innovative approaches to providing sustainable regenerative cellulose fibres. However, the latest climate change pressures on the textile industry has uncovered grave environmental issues associated with traditional regenerative cellulose production such as the viscose manufacturing process. The viscose process the required intensive use of hazardous chemicals which leads to water pollution and ecotoxicity. In addition, if forestry products are unsustainably sourced for the viscose production this can lead to resource scarcity and deforestation. To provide a holistic solution for mitigating these challenges this study uses the by-products of paper manufacturing dissolved in an ionic liquid to produce regenerated cellulose filaments. Paper mill sludge (PMS) is a cellulosic by-product typically used on animal bedding and land spreading. The material has been dissolved in an ionic liquid - 1-ethyl-3-methylimidazolium diethyl phosphate - with the aid of a co-solvent dimethyl sulfoxide (DMSO) - and spun into continuous filaments for textile production. The mechanical properties of paper sludge filaments are found to be competitive with commercial viscose, which is promising for their drop-in replacement. It is also demonstrated that by increasing the concentration of the PMS from 9\% to $12.4 \%$, an improvement of the filament properties can be achieved; an increase in modulus from $\sim 19 \mathrm{GPa}$ to $\sim 26 \mathrm{GPa}$ and $\sim 223 \mathrm{MPa}$ to $\sim 282 \mathrm{MPa}$. These values are shown to be competitive with other commercial, less sustainable, regenerated cellulose fibres.
\end{abstract}




\section{Introduction}

Fibres can be obtained from natural sources such as plants (cotton, hemp, ramie), animals (sheep wool, silk) and mineral (asbestos, rock wool). However, to ensure consistent quality and meet commercial demands fibres are typically man-made. These man-made fibres are grouped into two categories; regenerated or artificial fibres derived from cellulosic biomass or synthetic fibres derived from fossil fuel polymers. The global consumption of fibres comprises $66 \%$ synthetic fibres (polyester, nylon, acrylic), $27 \%$ cotton and $6 \%$ artificial fibres derived from regenerated cellulose (Freitas and Mathews, 2017). In 2016 regenerated fibres contributed to $6.6 \%$ of the 99 million tons of textile filaments consumed (Manian et al., 2018). Regenerated or artificial fibres are manufactured mainly using cellulose from wood pulp or cotton linters (Chen et al., 2006; Li et al., 2018).
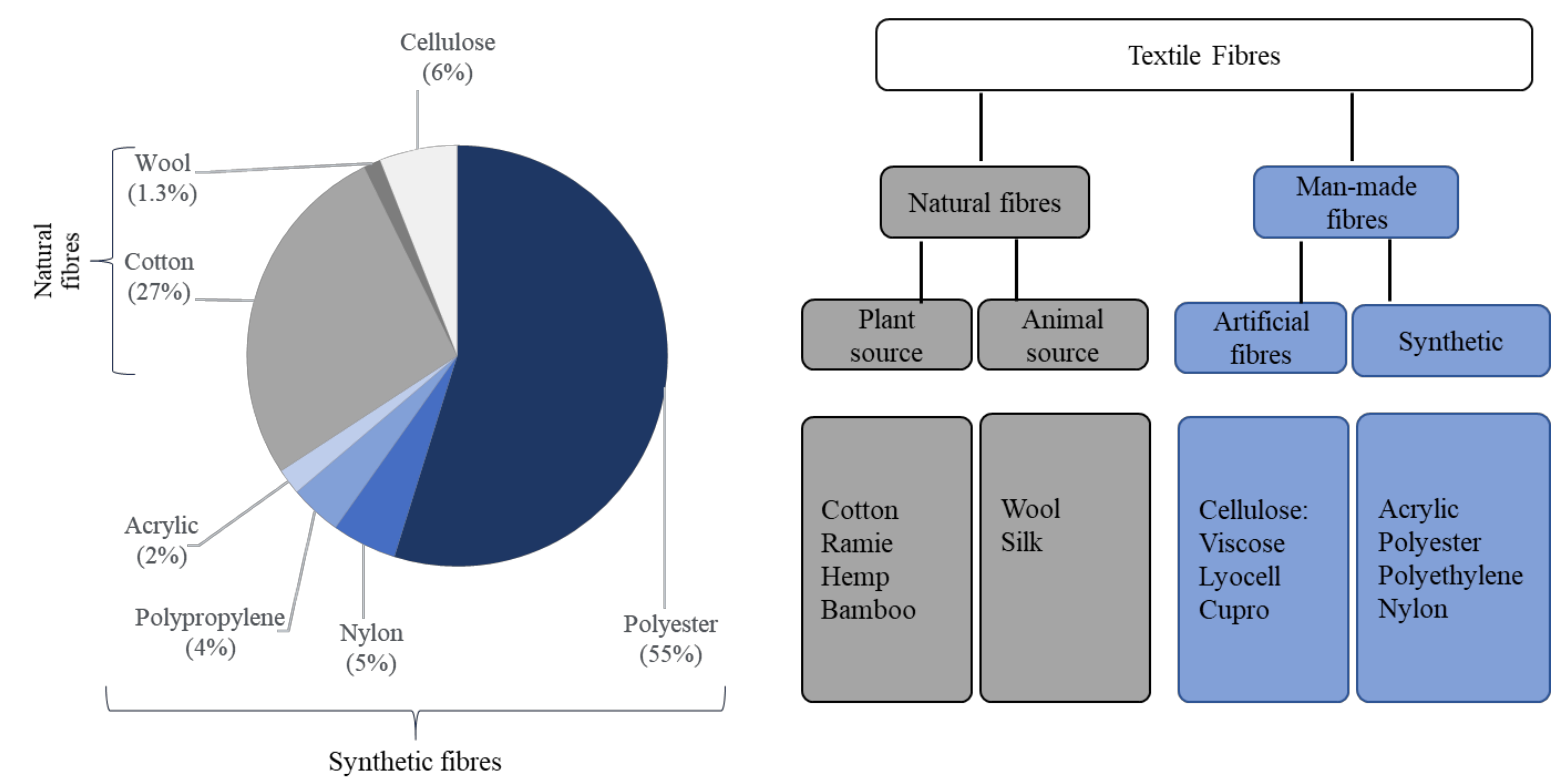

Fig.1. Overview of the textile industry fibre market and the sources of fibres. Data are obtained from (Textile Exchange, 2019)

Cellulose is an abundant natural polymer with a complex structure formed by repeating glucose units linked with intra/inter-molecular hydrogen bonds. It does not melt and is insoluble in most organic solvents. Therefore, efficient processing of regenerated cellulose has been limited to chemically intensive processes e.g. the viscose and lyocell processes. The viscose process requires sodium hydroxide $(\mathrm{NaOH})$ and treatment with carbon disulfide to produce cellulose xanthate. The cellulose xanthate is then dissolved in sodium hydroxide to form a spinning dope known as viscose (Wilkes, 2001). The viscose process is chemically intensive and creates toxic 
by-products such as hydrogen sulphide (H2S) and carbon disulphide (CS2). If proper environmental practices are not employed in a viscose factory it can lead to air emissions and pollution of public water systems. The exposure to these chemicals can also be linked to serious health conditions in factory workers (Sieja et al., 2018; Tan et al., 2001). The alternative lyocell process uses an N-methyl morpholine-N-oxide (NMMO) solvent instead to dissolve cellulose. This process produces high aligned fibres with improved fabric drape and breathability to inhibit bacterial growth.

Lyocell manufacturing is considered more environmentally friendly compared to the viscose process due to its high solvent recovery rate. However, lyocell fibres have low surface energy and require additional surface treatment to improve their substantivity to dyes (Senthil Kumar and Suganya, 2017; Shabbir and Mohammad, 2017). Moreover, NMMO is thermally unstable, and therefore requires significant financial investment to avoid exothermic reactions. There are also other negative side reactions from the process, including chromophore formation that results in fibre discoloration (Rosenau et al., 2001). As a result, lyocell fibres are more expensive to produce than viscose. A well-known brand, named Tencel ${ }^{\mathrm{TM}}$, adopts a closedloop production system to produce lyocell fibres, but is only produced for high-end markets.

Regenerated cellulose fibres can provide a sustainable alternative to synthetic fibres derived from fossil-fuels (Radhakrishnan, 2014; Yu and Wan, 2017). Nonetheless, hazardous chemicals are used in current production of regenerated cellulose fibres. Coupled with this, the resources consumed during viscose production are expected to double by 2050 . Whilst there are efforts made to adopt sustainable practices, today's textile industry still relies on the unsustainable production processes. Thus, alternative sources of regenerated cellulose produced using the less intensive processes will ultimately be beneficial to the textile industry.

As part of a search for a low cost and environmentally friendly alternative textile production process this study investigates the preparation of regenerated cellulose fibres by dissolving and spinning paper sludge in an ionic liquid (IL). Paper sludge is a by-product of the paper industry derived from the wastewater treatment process. The common management method of the sludge is for low value applications such as animal bedding and land spreading (Confederation of paper industries, 2014; Likon and Trebše, 2005; Monte et al., 2009) and in worst cases it is sent to landfill. However, paper sludge is a source of cellulose that can be processed as an input into the textile industry. Several studies in the cleaner production literature have used waste 
materials such as cotton waste garments (Haule et al., 2016), cotton waste pulp (Björquist et al., 2018) office paper and cardboard waste (Ma et al., 2016a) for fibre production however paper sludge has not been investigated. Ionic liquids have been recently proposed in the textile industry as green solvents for mitigating environmental issues.

Ionic liquids (ILs) have attracted attention as a one-step process for dissolving cellulose at low temperature (Swatloski et al., 2002). The anions in ILs are hydrogen bond acceptors that strongly interact with the free hydroxyl groups in the repeating glucose units of cellulose. This results in dissociation of the intra/inter-molecular hydrogen bonds and aids the dissolution of cellulose. ILs also have numerous advantages, such as thermal stability, non-flammability and easy recoverability (Isik et al., 2014; Wendler et al., 2012). Early studies presumed that only the anions in the ILs played a significant role in forming bonds to aid dissolution (Remsing et al., 2008; Swatloski et al., 2002). A later study aimed to understand the dissolution of cellulose in ILs by comparing the hydrogen bonding of cellulose in various solvents; 1-ethyl-3methylimidazolium acetate (EMImAc), water and ethanol (Liu et al., 2010) The hydrogen bonds formed by the hydroxyl groups of cellulose and -OAc anions of IL revealed a stronger interaction (Liu et al., 2010). Additionally, the imidazolium cations also formed van der Waals interactions with the repeating D-glucose units of cellulose which aids dissolution.

Filaments have been spun from various sources such as banana rachis waste, kraft pulp CNF suspension without dissolution (Ghasemi et al., 2017; Hooshmand et al., 2015). Higher concentrations of CNFs have also been spun over wider concentration ranges $(1-10 \%)$ (Clemons, 2016; Lundahl et al., 2017). However, the filaments obtained in previous studies have been limited to large diameters $(>100 \mu \mathrm{m})$ which are not commercially viable for all textile production. Nonetheless, ILs provide the opportunity to dissolve and spin higher concentrations of cellulose, but also retain smaller diameters which are necessary for textile and composite applications. To this end, 18\% microcrystalline cellulose (MCC) has been dissolved in 1-ethyl-3-methyl-limidazolium diethyl phosphate (EMImDEP) using a dry-jet wet spinning method, leading to significant increase in mechanical properties and smaller filament diameters of 20-23 $\mu \mathrm{m}$ (Zhu et al., 2016). Moreover, using dimethyl sulfoxide (DMSO) as a co-solvent was proven to facilitate the dissolution process allowing spinning up to $\sim 24 \%$ cellulose (Zhu et al., 2018). 
In the present study, CNF were prepared from sludge derived from waste-water treatment of paper mill. These fibrils were dissolved in a 50:50 EMImDEP:DMSO solvent mixture, and a continuous filament was extruded using a dry-jet wet spinning method to produce regenerated cellulose filaments. Although this means dissolving the CNF into a solution, losing the filamentous properties of the extracted material, it does enable a continuous fibre to be spun. In addition, the use of a highly oriented, purified, and crystalline precursor material, extracted from waste, is thought to be a sustainable use of an otherwise waste product from paper mills.

\section{Materials and methods}

Two solutions were prepared for fibre spinning, by dissolving 9\% CNF and $12.4 \% \mathrm{CNF}$ in a 50:50 EMImDEP:DMSO solvent mixture respectively as illustrated in Figure 2.

\subsection{Materials}

The paper sludge, obtained from a kitchen towel mill, was dispersed in water and mechanically homogenized using a supermass colloider MKCA6-3 (Masuko Sangyo Co, Japan) to prepare CNF fibres as described in an earlier study (Adu et al., 2018). The chemical composition of the CNF was $74 \%$ cellulose, $2.6 \%$ hemicellulose, as well as inorganic minerals including Ca (947 $\mathrm{mg} / \mathrm{kg})$, Si (3694 mg/kg), Mg (1578 mg/kg) and Fe (166 mg/kg). The CNF had an average width of $50 \mathrm{~nm}$, crystallinity index of 43\%. The EMImDEP (IL-0052) was purchased from IoLiTec Ionic Liquids Technologies GmbH, Germany. The co-solvent DMSO (D/4121/PB08) was purchased from Fisher Scientific, UK.

\subsection{Dissolution of $C N F$}

A $3 \mathrm{wt} \%$ CNF suspension prepared from paper sludge by mechanical homogenisation was frozen at $-20{ }^{\circ} \mathrm{C}$ for $24 \mathrm{hrs}$. The frozen suspension was freeze dried at a temperature of $-52{ }^{\circ} \mathrm{C}$ and a pressure of $0.1 \mathrm{~Pa}$ using a Biolab benchtop freeze dryer (Biolab, Canada). Freeze drying was used for the removal of water from $\mathrm{CNF}$, avoiding fibre agglomeration and easing the miscibility with the IL. Then, $2.7 \mathrm{~g}$ dried (9\% CNF respect to solvent) and $3.7 \mathrm{~g}(12.4 \% \mathrm{CNF}$ respect to the solvent) were added to a 30 g 50:50 EMImDEP:DMSO solvent mixture respectively (Figure 2). This solution was heated in an oil bath at $100{ }^{\circ} \mathrm{C}$ under magnetic stirring - $50 \mathrm{rpm}$ for 8 hours. The CNF was considered dissolved when the solution appeared clear with no solid particles present. 


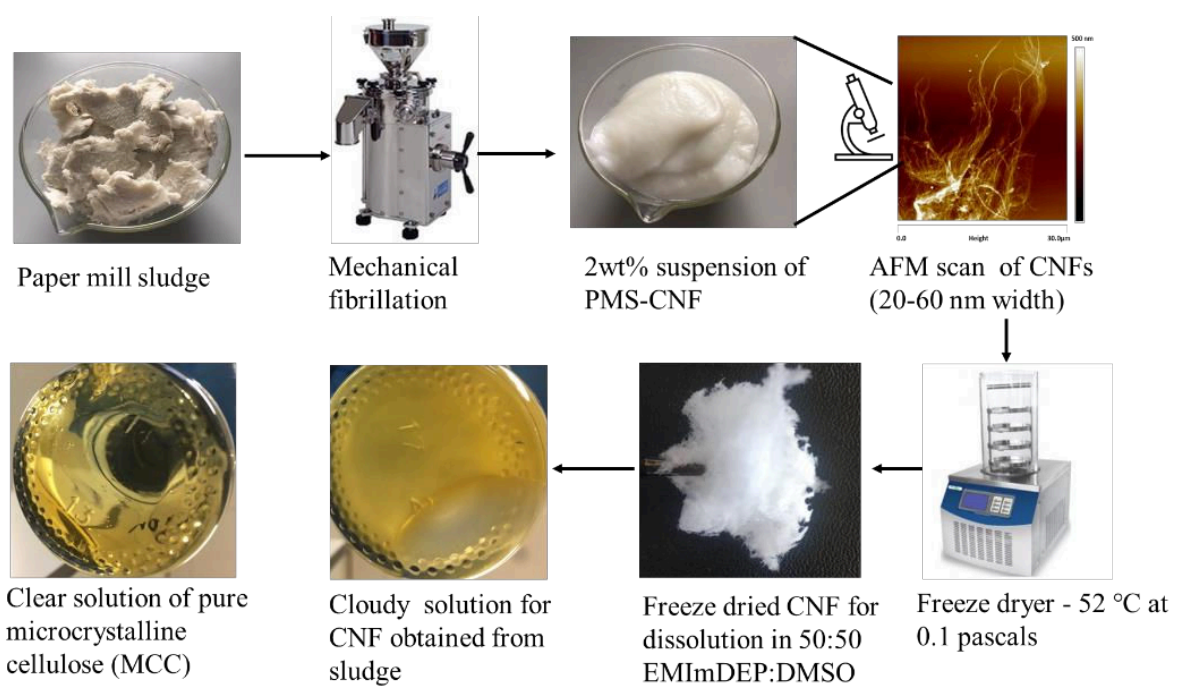

Fig.2. Schematic of the paper mill sludge preparation into CNF for dissolution in a 50:50 EMImDEP:DMSO solution shown alongside a solution of pure microcrystalline cellulose dissolved directly in EMImDEP:DMSO.

\subsection{Spinning of CNF into filaments}

A schematic of the dry-jet wet spinning equipment used to manufacture the cellulose filaments is shown in Figure 3. This consists of a vertical compression extruder with a $10 \mathrm{kN}$ load cell, water bath and winding unit. The solution was decanted into an extruder barrel and degassed in a vacuum oven at $100{ }^{\circ} \mathrm{C}$ for two hours. The degassed solution was dry-jet wet spun at 50 ${ }^{\circ} \mathrm{C}$ through a single-hole nozzle with a diameter of $150 \mu \mathrm{m}$. The velocity at the nozzle outlet (V1) was $0.3 \mathrm{~m} / \mathrm{s}$ whilst the velocity (V2) of the winder was $0.8 \mathrm{~m} / \mathrm{s}$, giving a draw ratio $(\mathrm{V} 2 / \mathrm{V} 1)$ of 2.5 . The air gap was set to $1 \mathrm{~cm}$. The spun filaments were immersed in water at room temperature for $24 \mathrm{hrs}$ prior to drying, to remove any ionic liquid present in the fibres. The air gap aids the orientation of the filaments by exerting extensional stress, which induces the molecular orientation of cellulose polymer chains along the spinning axis (Qin et al., 2001).

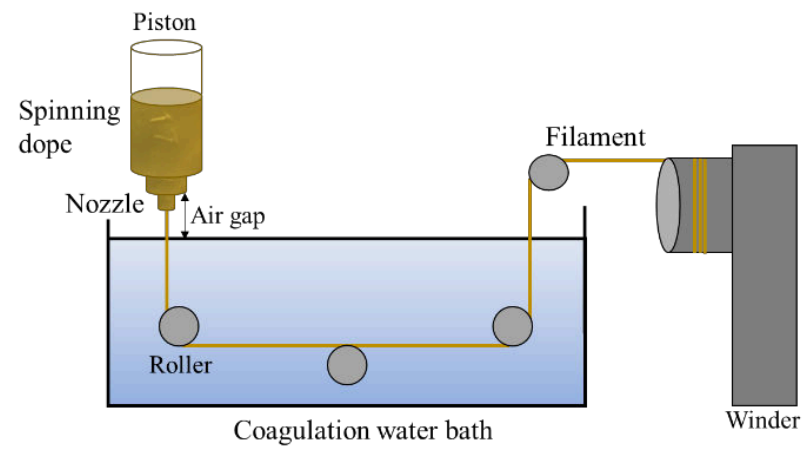

Fig.3. Schematic of the dry-jet wet spinning process 


\subsection{Characterization of spinning dope}

Filament spinning is influenced by the temperature-dependent viscosity of the solution. Therefore, the viscosity of the spinning dope was measured in steady and oscillatory shear studies at $100{ }^{\circ} \mathrm{C}$ (dissolution temperature) and $50{ }^{\circ} \mathrm{C}$ (spinning temperature) respectively. Viscosity measurements were obtained with a Discovery HR-1 rheometer (TA instruments, USA). The spinning dope was deposited between a Peltier plate and a $40 \mathrm{~mm}$ diameter stainless steel cone-plate with a $4^{\circ}$ angle. The set gap was $97 \mu \mathrm{m}$ and the specimen was soaked for 60 seconds at $100{ }^{\circ} \mathrm{C}$ before starting the rheology experiment. Rheology data were collected using Trios software (TA instrument).

\subsection{Characterization of filaments}

The filament morphology was characterised using a scanning electron microscope (SEM), model JSM-6490LV, JEOL (Japan). Cross-sections were observed from 5 filaments per sample. All filaments were frozen in liquid nitrogen at $\left(-180{ }^{\circ} \mathrm{C}\right)$ and snapped with tweezers before SEM analysis. Energy dispersive X-ray (EDX) spectroscopy was used to acquire an elemental spectrum of the filament and the data was processed with Oxford Instruments' Aztec ${ }^{\mathrm{TM}}$ EDS element mapping software. The crystallinities of the cellulose filaments were calculated using both Segal's method and peak fitting method from the wide-angle X-ray diffraction (WAXD) and powder X-ray diffraction data. Segal's method (Segal et al., 1958) has recently been critiqued by French (French, 2014) however we include values derived using this method for comparison with other work published in the literature. For WAXD, a SAXSLAB GANESHA 300 XL SAXS system (SAXS LAB, Denmark) was used. Powder X-ray diffraction data were acquired using a Bruker D8 ADVANCE X-ray diffractometer (Bruker Co., Germany). For mechanical testing, 10 filaments from each sample were mounted with DYMAX 3193 UV adhesive (Wiesbaden, Germany) on a plastic tabs with notches using a $2 \mathrm{~cm}$ gauge length cassette. The ends of the filament were adhered to plastic which have notches used keep the filament straight without tension. The mounted filaments were left under UV light for $2 \mathrm{hrs}$ to allow the adhesive to cure. The filaments are removed with a suction device and transferred to the instrument holder whilst remaining on the plastic tabs. The diameter measurements of the samples were obtained with a Dia-stron FDAS770 fibre dimensional analyser (Dia-stron, UK) at 5 separate locations along the filaments. The tensile test was conducted with a Dia-stron LEX820 (Dia-stron, UK) single fibre tester with a $20 \mathrm{~N}$ load cell. 


\section{Results and discussions}

\subsection{Rheology of the spinning dope}

The viscosities of the $9 \%$ and $12.4 \%$ spinning dope were 8.2 and $51.3 \mathrm{~Pa} \cdot \mathrm{s}$ at $100{ }^{\circ} \mathrm{C}$ during dissolution. During fibre spinning, the temperature was reduced to $50{ }^{\circ} \mathrm{C}$ to increase the viscosity of the solution for the formation of filaments. At $50{ }^{\circ} \mathrm{C}$, the viscosities increased to 45.7 and 329.0 $\mathrm{Pa} \cdot \mathrm{s}$ as shown in Figure 4. The solutions show a Newtonian regime until they exhibit shear thinning at an angular frequency of $23 \mathrm{rad} \mathrm{s}^{-1}$. (Figure 4b) This shear thinning is thought to occur due to polymer chain disentanglement, deformation and orientation parallel to the driving force which breaks up any aggregated structures in the spinning dope (Schramm, 1998; Wang et al., 2008). At 100 and $50{ }^{\circ} \mathrm{C}$, the dynamic viscosities at $0.5 \mathrm{rad} / \mathrm{s}$ are 4.5 and 17.1 $\mathrm{Pa} \cdot \mathrm{s}$ for a $9 \% \mathrm{CNF}$ solution, and 24 and $100 \mathrm{~Pa} \cdot \mathrm{s}$ for the $12.4 \% \mathrm{CNF}$ solution. The increase in $\mathrm{CNF}$ concentration and a decrease in temperature both resulted in viscosity increases of the spinning dopes as shown in Figure 4. This may be caused by molecular entanglement restricting the freedom of movement between individual chains.
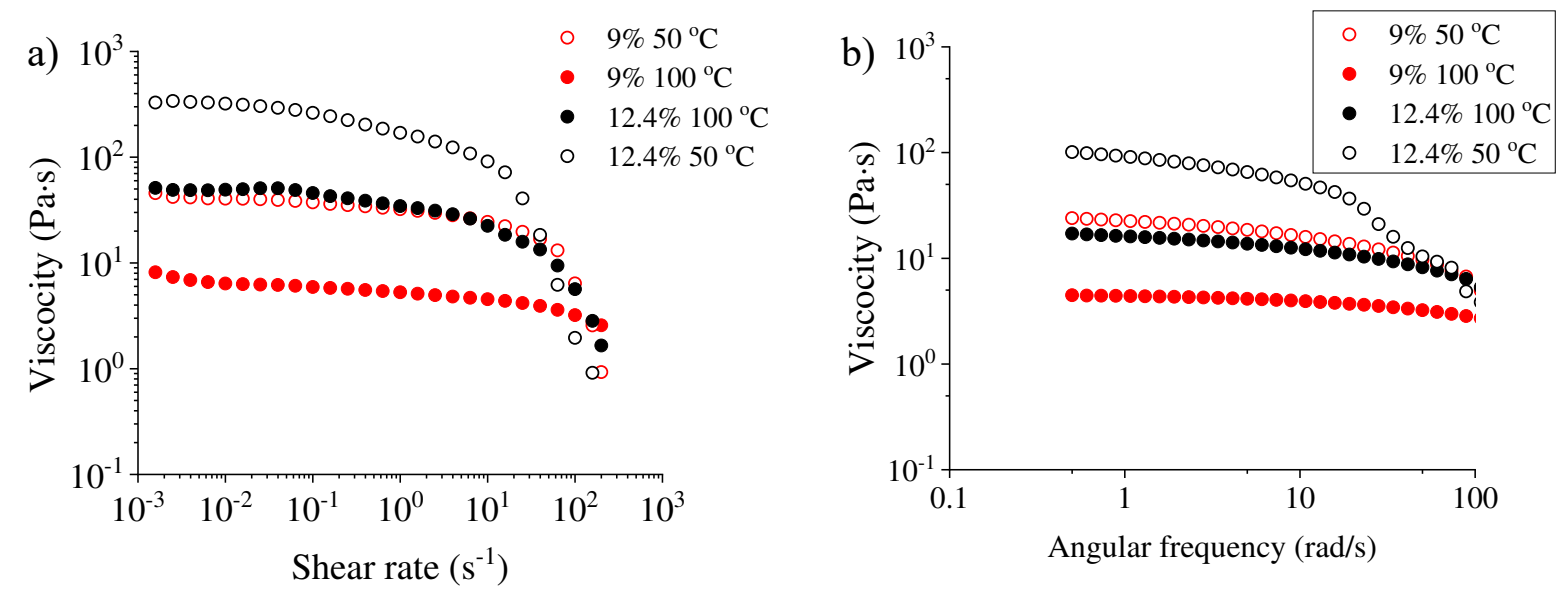

Fig.4. Viscosities of spinning dopes: a) steady shear and b) oscillatory shear at 50 and 100 ${ }^{\circ} \mathrm{C}$.

The Cox-Merz relationship explains that steady shear viscosity $(\eta)$ can be estimated from the dynamic viscosity $\left(\eta^{*}\right)$ if both curves coincide or overlap (Cox, P and Merz, H, 1958). Thus, overlaying these traces can be used to predict viscosity at a higher shear rate. Yuan (2015) showed that cellulose/BMImCl solutions supported the Cox-Merz rule for a shear rate up to $100 \mathrm{~s}^{-1}$ with a deviation as the concentration increased. Wang et al. (2008) also showed that for cellulose in AMImCL, $(\eta)$ and $\left(\eta^{*}\right)$ only coincided in the Newtonian regime. The overlaying of the cellulose spinning dopes viscosities in Figure 5 did not follow the Cox-Merz relationship. 
Deviation from the Cox-Merz rule can be attributed to cellulose aggregation and poor dispersion at the molecular level (Haward et al., 2012), which is assumed to be occurring with our solutions. Further work would therefore be required to achieve better dispersion, but this might only come with purer solutions of dissolved cellulose. This is perhaps one downside to using waste material for the dissolution process.
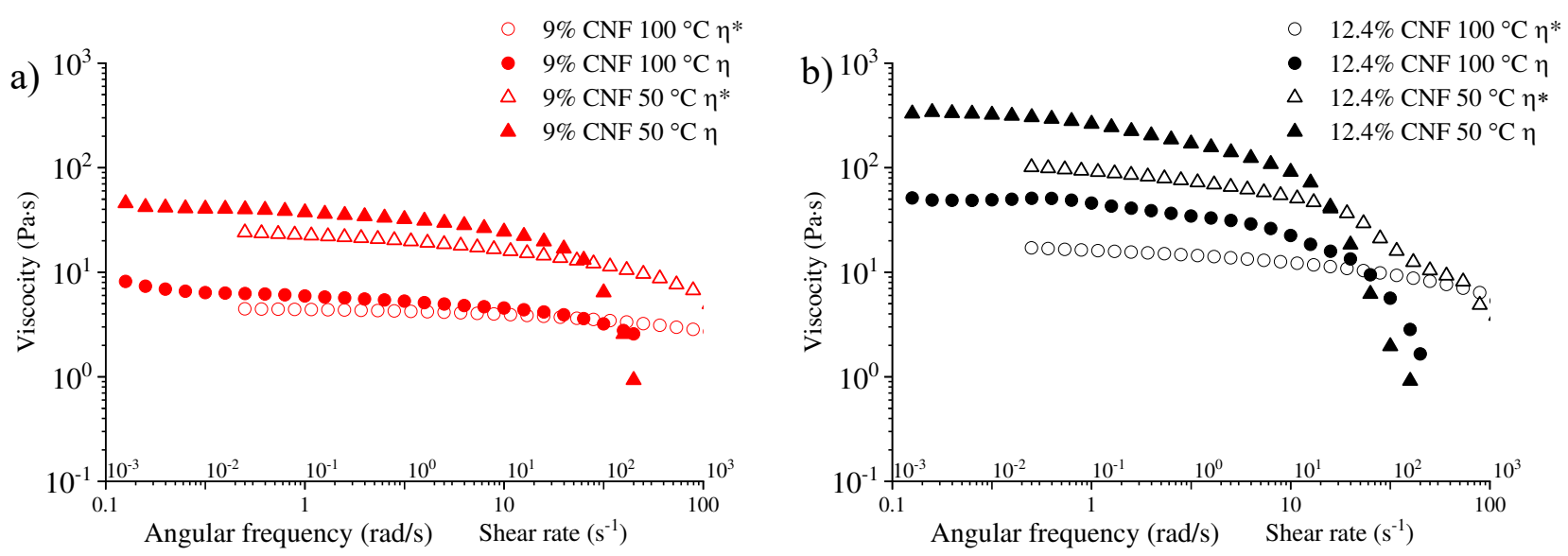

Fig.5. Overlay of $50^{\circ}$ and $100{ }^{\circ} \mathrm{C}$ steady shear viscosity and dynamic viscosity of $9 \%$ cellulose spinning dopes (a), and 12.4\% cellulose spinning dopes (b).

\subsection{Imaging of the IL Spun Filaments}

The filaments were imaged in the SEM, showing a homogenous morphology along their lengths (Figure 6). The outer surface of the filaments revealed longitudinal striations similar to lyocell fibres.
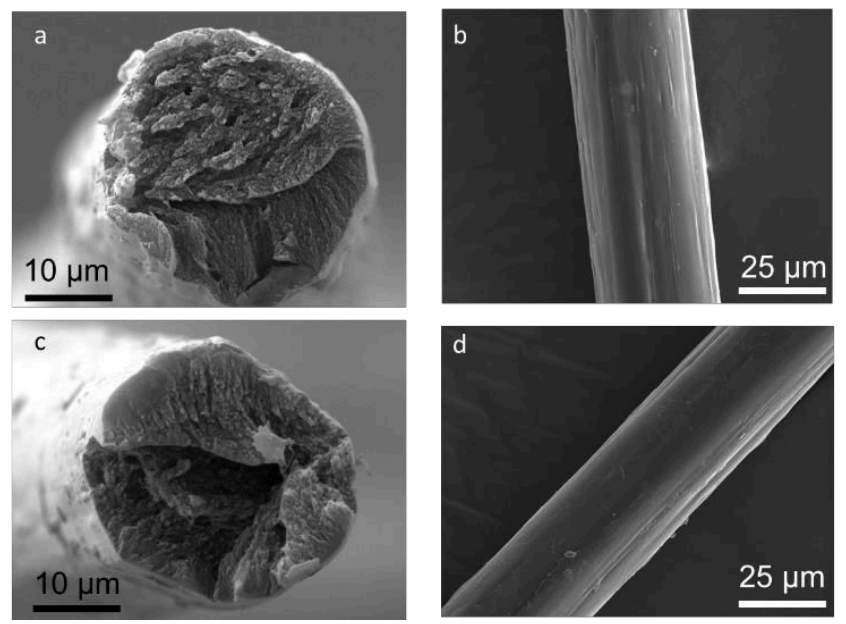

Fig. 6. Typical SEM images of spun cellulose fibres; (a) 9\% cross-section, (b) $9 \%$ outer surface, (c) $12.4 \%$ cross-section and (d) $12.4 \%$ outer surface. 
The diameters of the filaments, from the cross-sections, were found to be $31.3 \pm 2.1 \mu \mathrm{m}$ and $24.7 \pm 1.1 \mu \mathrm{m}$ for $9 \%$ and $12.4 \%$ concentrations respectively. Some of the filaments had particles deposited on their surfaces which might be due to undissolved inorganic minerals. EDX spectra were recorded both from the cross-sections of the filaments, and from their outer surfaces. Calcium (Ca), magnesium (Mg), aluminium (Al) and silicon ( $\mathrm{Si})$, shown in the EDX spectra (Figure 7) are common fillers used to enhance opacity, smoothness and dimensional stability in paper production.

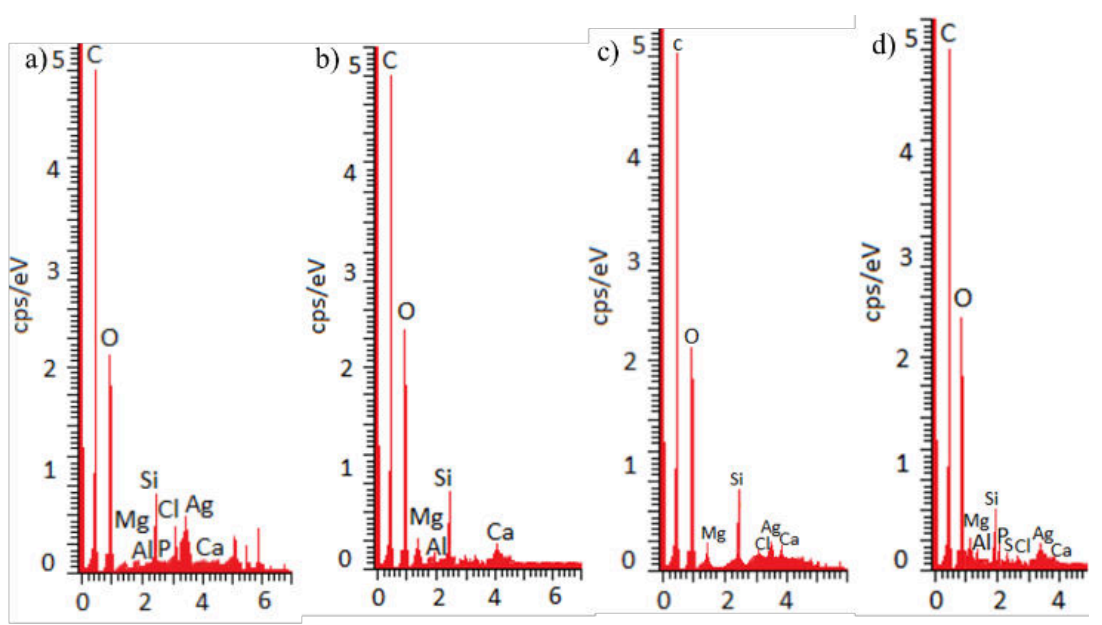

Fig. 7. EDX scans of the cellulose filaments revealing presence of inorganic minerals on the cross sections of a) $9 \%$ and b) $12.4 \%$ filament, and the outer surfaces of c) $9 \%$ and d) $12.4 \%$ filament.

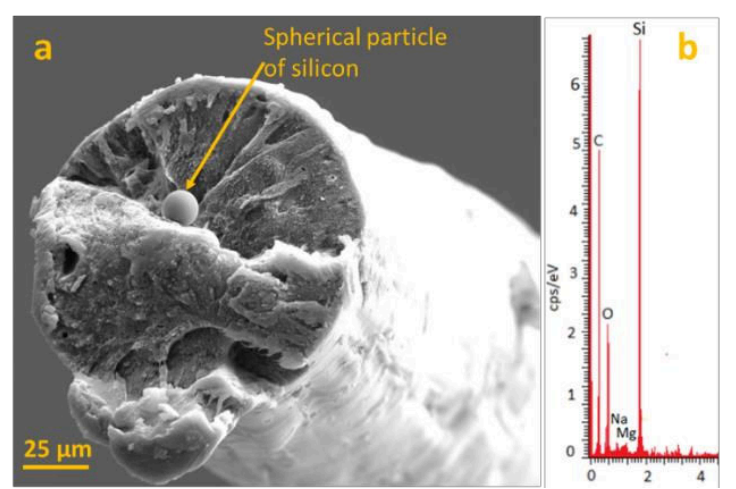

Fig. 8. An SEM image of a broken cellulose filament (a) after tensile tests showing a spherical particle (arrow) of $\sim 3 \mu \mathrm{m}$ (b) EDX spectrum of the filament cross-section confirming particle as silicon.

These minerals most likely remain undissolved in the IL, and could interfere with the fibre production thereby limiting their tensile strength; the presence of an impurity is shown in Figure 8. 


\subsection{Mechanical Properties of Spun Filaments}

Typical stress-strain curves for the spun filaments are shown in Figure 9. They exbibit typical non-linear behaviour, seen for many regenerated cellulose fibres, with a yield point occurring $\sim 1 \%$. The average tensile strengths of the filaments were $223 \pm 35 \mathrm{MPa}$ and $282 \pm 40$ for $9 \%$ and $12.4 \%$. CNF respectively. The filaments exhibited strains to failure of $4.0 \pm 1.4 \%$ and 2.5 $\pm 1.1 \%$ with moduli of $19.9 \pm 1.3 \mathrm{GPa}$ and $25.9 \pm 1.8 \mathrm{GPa}$. The increase in CNF concentration led to improvements in the filament strength and modulus although this reduced the strain to failure of the filament. These values compare favourably to other regenerated cellulose fibres, with typical values in the range 15-30 GPa for modulus, and strengths of 200-700 MPa (Eichhorn et al., 2001).

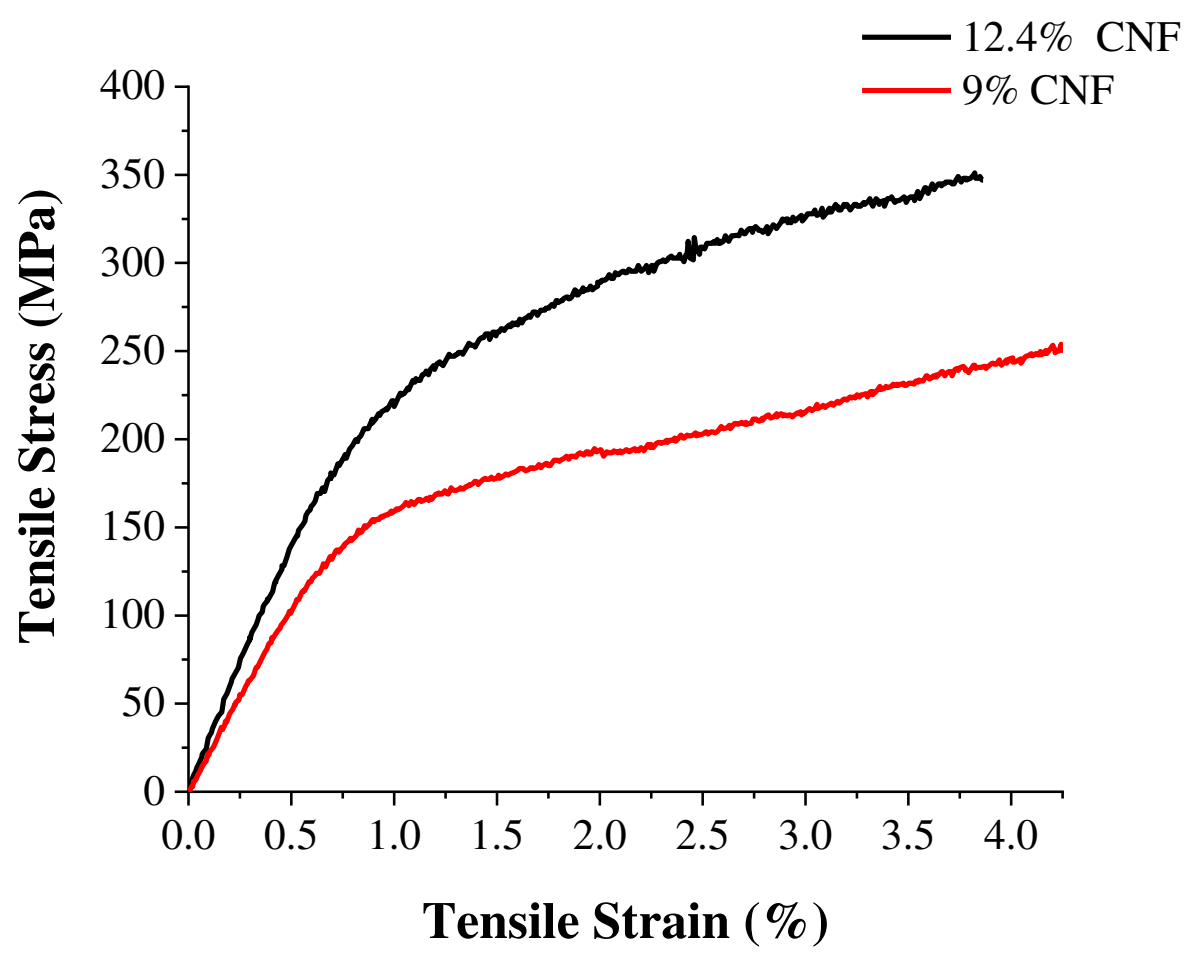

Fig. 9. Typical stress-strain curves of $9 \%$ and $12.4 \%$ cellulose filaments.

\subsection{Powder X-ray and wide-angle X-ray diffraction of CNF filaments}

The crystallinity index determined from the powder X-ray diffractograms, as shown in Figure 10 , resulted in $62 \%$ and $44 \%$ for the $9 \%$ and $12.4 \%$ cellulose filaments. These X-ray diffraction patterns are typical of a cellulose-II structure. The crystallinity also reduced at higher CNF concentration, as derived from the WAXD pattern in Figure 11. It is not known why a lower 
crystallinity is obtained for filaments produced at a higher cellulose concentration. Higher crystallinity is thought to increase the stiffness of the filament although this leads to brittleness and reduction in tensile strength. The full width at half maximum (FWHM) was calculated from the WAXD azimuthal scanning data of the (110) peak (see supporting information Figure S3). The FWHM for $9 \%$ and $12.4 \%$ were $29.22^{\circ}$ and $27.25^{\circ}$ respectively. The $12.4 \%$ filament showed increased fibre alignment which can be associated with an increased modulus and tensile strength.
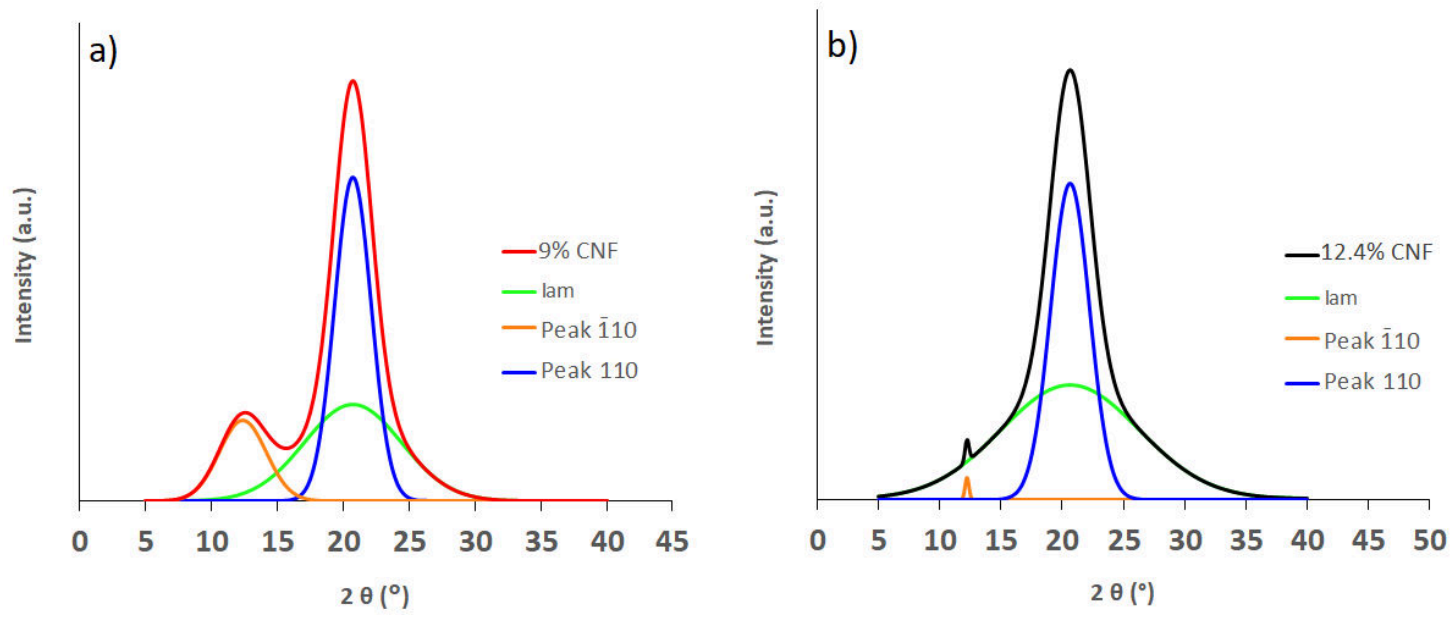

Fig. 10: Typical deconvoluted powder X-ray diffraction peaks; a) 9\% cellulose and b) $12.4 \%$ cellulose (right) derived filaments.

a)

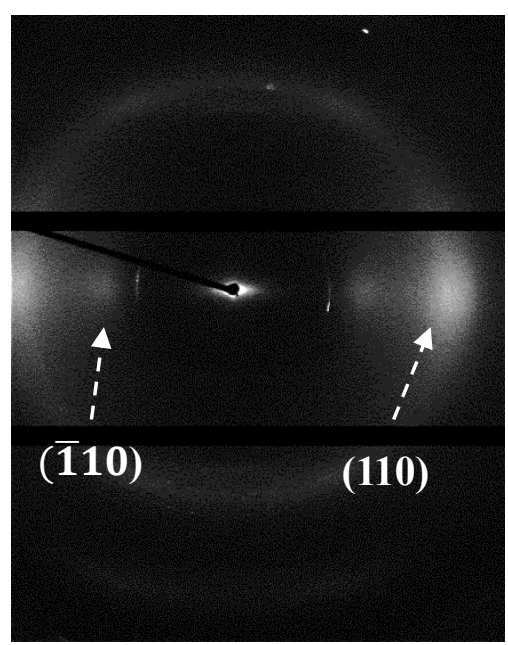

b)

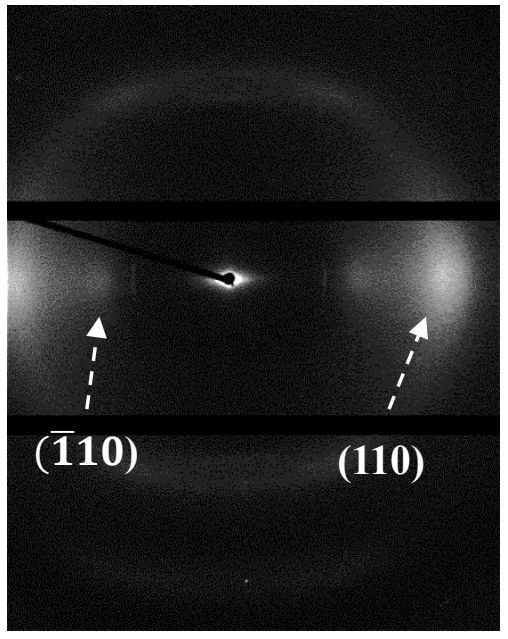

Fig. 11. WAXD pattern of a) $9 \%$ and b) $12.4 \%$ filaments. 


\subsection{Filament orientation parameters}

The orientation parameter $(f)$ describes how well the crystallites are aligned (Northolt, 1980; Northolt and Baltussen, 2002; Northolt and van Aartsen, 1977). This parameter is defined as the mean of the second-order Legendre polynomial, $\mathrm{P}_{2}(\cos \theta)$, where $\theta$ is the polar disorientation angle of a crystallite relative to the fibre axis and the angle brackets indicate an average over all crystallites, according to the equation

$$
f=\left\langle P_{2}(\cos \theta)\right\rangle=(-2) \frac{\int_{0}^{\pi} \rho(\varnothing) P_{2}(\cos \emptyset) \sin \emptyset d \emptyset}{\int_{0}^{\pi} \rho(\varnothing) \sin \emptyset d \emptyset}
$$

where $\rho(\varnothing)$ is the distribution of intensity in the $(\overline{1} 10)$ peak as a function of the azimuthal angle, $\varnothing$, with respect to the fibre axis. If $f=1$ there is a complete alignment of the cellulose crystallites parallel to the fibre axis; $f=-0.5$ indicates a perpendicular orientation to the fibre axis and $f=0$ is a random orientation. This equation has previously been applied to determine the crystallite orientation of regenerated cellulose fibres (Eichhorn et al., 2003; Zhu et al., 2016). The orientation parameters for the present fibre samples were calculated from the azimuthal scanning data as 0.70 and 0.74 for the $9 \%$ and $12.4 \%$ filaments respectively. Both these values indicate a high degree of orientation to the crystallites within the structure of the fibres, and are similar to other values obtained in the literature, noting that $\left(1-\sin ^{2} \theta\right)$ equivalent to $\operatorname{Cos}^{2} \theta$

\section{Table 1}

Summary of cellulose filaments properties for average SEM diameter, Crystallinity Index (CrI), Full Width at Half Maximum (FWHM) of peak (110), Orientation parameter $(f)$ of peak (110), Young's modulus and Tensile strength of $9 \%$ and $12.4 \%$ cellulose filaments.

\begin{tabular}{|c|c|c|c|c|c|c|}
\hline $\begin{array}{c}\text { Fibre } \\
\text { sample }\end{array}$ & $\begin{array}{c}\text { Diameter } \\
(\mu \mathrm{m})\end{array}$ & $\begin{array}{c}\text { CrI } \\
(\%)\end{array}$ & $\begin{array}{c}\text { FWHM } \\
(\mathrm{deg})\end{array}$ & $\begin{array}{c}f \text { of peak } \\
(\overline{110})\end{array}$ & $\begin{array}{c}\text { Young's } \\
\text { modulus } \\
(\mathrm{GPa})\end{array}$ & $\begin{array}{c}\text { Tensile } \\
\text { strength } \\
(\mathrm{MPa})\end{array}$ \\
\hline $\mathbf{9 \%} \mathbf{C N F}$ & $31.3 \pm 2.1$ & 62 & 29.22 & 0.70 & $19.9 \pm 1.3$ & $223 \pm 35$ \\
\hline $\begin{array}{c}\mathbf{1 2 . 4 \%} \\
\mathbf{C N F}\end{array}$ & $24.7 \pm 1.1$ & 44 & 27.25 & 0.74 & $25.9 \pm 1.8$ & $282 \pm 40$ \\
\hline
\end{tabular}

An Ashby plot of the cellulose filaments and other spun fibres is shown in Figure 12. The Young's moduli of the $9 \%$ and $12.4 \%$ cellulose filaments are higher than commercial viscose 
Enka $^{\mathrm{TM}}$ fibres (10-12 GPa) whilst the tensile strength of the $12.4 \%$ filament is also competitive. The cellulose filaments are inferior to MCC filaments spun with the same ionic solvent and dry-jet wet spinning method (Zhu et al., 2018). This inferiority is mainly due to their dissolution of pure MCC at high concentrations (20.8\% and 23.6\%) leading to the formation of liquid crystalline (LC) phases of the cellulose solutions, resulting in a high degree of filament alignment $(f=0.80-0.84)$. These values of $f$ are much higher than the present filaments $(\sim 0.7)$, which may be the reason for the lower mechanical properties. We have no evidence for the formation of LC phases for the present IL/cellulose solutions. This limited orientation may be due to the reduced ability to shear thin the solutions, as seen by the lack of adherence of the viscosity-shear data to the Cox-Merz rule. It was also found that at a lower concentration the fibres have a higher diameter than those spun at a higher concentration. This may be because of die-swelling during the spinning process, which could be supressed with an increased cellulose concentration and thereby a higher entanglement density of the chains.

Despite the limitations of the tensile strength of the sludge derived CNF filament properties, due to the presence of inorganic minerals, some studies have achieved higher mechanical properties (purple) from dissolution and spinning of waste paper which contained minerals; $\mathrm{Ca}$ (340 mg/kg), Si (210 mg/kg), Mg (14 mg/kg) and Fe (29 mg/kg) (Ma et al., 2016b). This was achieved due to pre-treatment with dynamic drainage jar and tailored ionic solvent to dissolve the inorganic minerals thus the mineral concentration was substantially lower than the present sludge CNF. The sustainability credentials of ionic liquids are questionable, unless they can be recycled in a manufacturing process. Some work has been invested into the recycling of ionic liquids (Anugwom et al., 2014), whereby they can be recovered following evaporation of the antisolvent. In our case we also use a DMSO co-solvent, which has been demonstrated to be recoverable in an aqueous system (Zajáros et al., 2018). Although this was not in the presence of an ionic liquid. More research would have to be invested into looking at recycling this mixed solvent system, or using a 'greener' solvent, such as gamma-valerolactone (Lê et al., 2019). Other issues around the sustainability of the processing are that it ought to be possible to go directly from the paper-mill sludge to a spun fibre system, without the need for high energy intensive processing into cellulose fibrils. We attempted to do this but found limited solubility of the sludge directly into the ionic liquid, possibly due to the presence of additives and impurities from the papermaking process. It is possible to remove these additives using several filtration cycles, bleaching, and a bespoke ionic liquid (Ma et al., 2016b) but this level of processing is thought to be just as energy intensive as fibrillating and purifying a cellulose 
fraction. It could be possible to further refine the sludge, to a microfibrillated form of cellulose, before dissolution, but this remains a topic for future research. Even in this refined form, impurities may still cause issues with fibre spinning, so fractionation will be necessary.

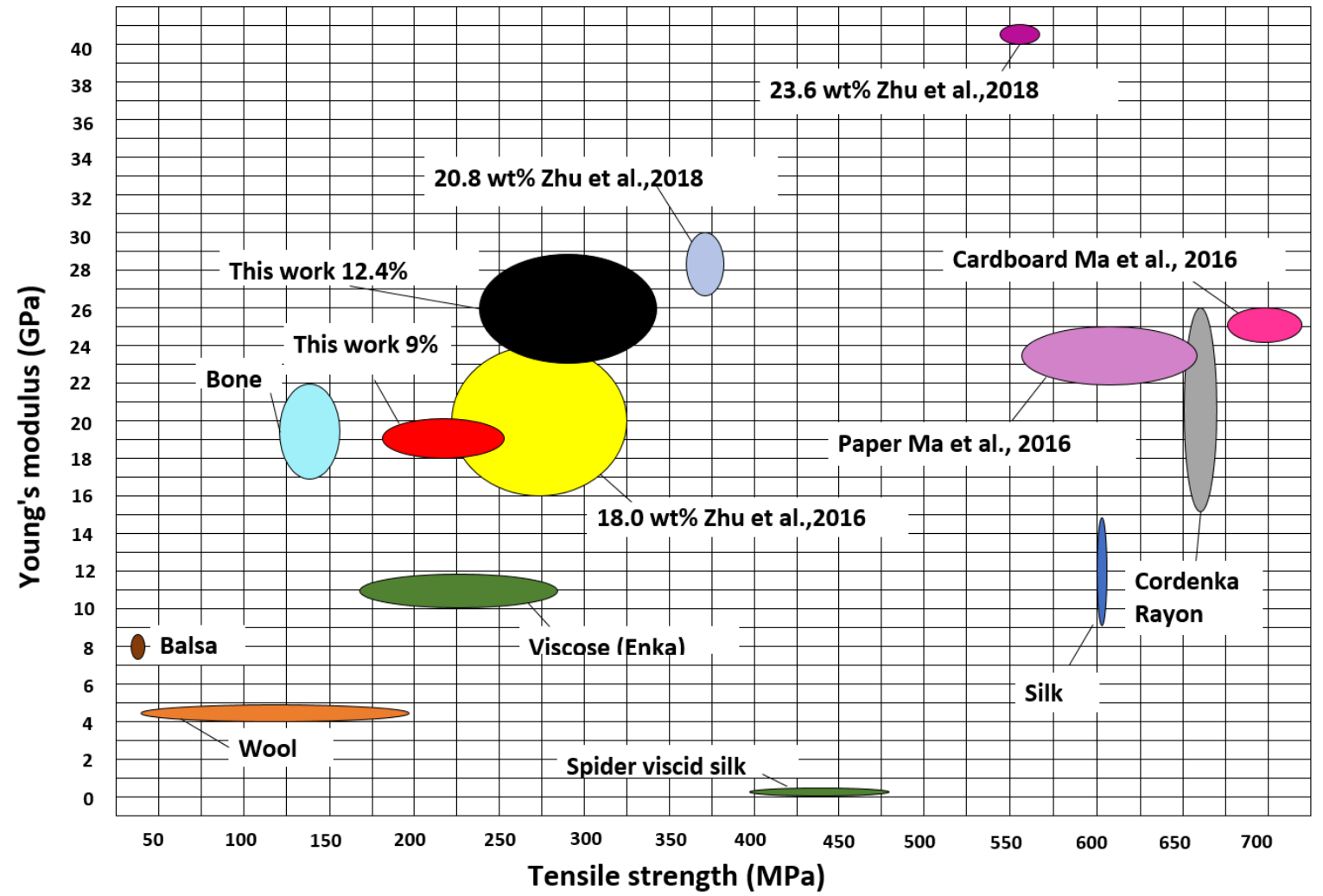

Fig. 12. Ashby plot of $9 \%$ (red) and $12.4 \%$ (black) sludge CNF filaments in comparison with cellulose filaments from the literature, natural and commercial regenerated fibres (see table s3 in supporting information for raw data)

\subsection{Implication for theory and practice}

Whilst the mechanical properties of the filaments spun in this work are competitive there are still some economic considerations for a practical scaling of production. The cost of viscose staple fibre is approximately $£ 1,100$ per tonne whereas the current cost of producing the paper sludge filaments is significantly higher due to the cost of ionic liquid. The solvent used in this work - 1-Ethy-3-methylimidazolium diethyl phosphate - currently costs $£ 175$ per $100 \mathrm{~g}$, reducing to $£ 888$ per $1 \mathrm{~kg}$ of solution (Sigma-Aldrich). Although cost is driven down due to economies of scale, the dissolution solution ratio used in this work is $3.7 \mathrm{~g}$ of fibres in $30 \mathrm{~g}$ of solution, given a ratio of 1:8. Since we used DMSO in to aid dissolution, and to reduce the cost of the ionic liquid, this bring the ratio of fibre to ionic solvent to 1:4. Therefore, to produce 1 tonne of fibre and remain cost effective a high recovery rate of solvent at $99 \%$ and at least 4065 times of ionic solvent reuse is required to remain cost effective. Furthermore, other costs such 
as the cost of electricity for dissolution, the cost of DMSO and energy costs for recovering the solvent have not been factored in. Despite paper mill sludge being a cheap by-product, and in some cases cost negative, the use of ionic solvent is still not economically viable. Therefore, more research will have to be invested in producing cost-effective ionic liquid, and its recovery in process, for the true environmental benefits to be realised.

\section{Conclusions}

This study demonstrates the possibility of upcycling cheap paper mill sludge, first into fibrillar material, then by dissolving this in an ionic liquid, and spinning a solution into long filaments for textile applications. Ionic liquids present a benign method to produce spun fibres like viscose without detriment to the environment. However, the high cost of the solvent at present limits commercial potential. The 50:50 EMImDEP:DMSO ratio and the use of a free byproduct from paper mills without any further chemical treatment present an opportunity for a sustainable business case to compete with viscose fibre production. The tensile strength of the filament increased from $223 \pm 35 \mathrm{MPa}$ at $9 \% \mathrm{CNF}$ to $282 \pm 39.6 \mathrm{MPa}$ at $12.4 \% \mathrm{CNF}$. The $9 \%$ CNF fibres had similar tensile strengths to commercial viscose (Enka) fibres. However, increasing the CNF concentration to $12.4 \%$ resulted in higher tensile strengths. The moduli of the $9 \%$ and $12.4 \%$ CNF filaments are both higher than commercial viscose (Enka) (10-12 GPa). CNF from paper sludge contains a high amount of inorganic material, which is found to remain undissolved, thereby affecting the mechanical properties of the filaments. Filtration of this material, or the use of a tailored ionic solvent that can dissolve inorganic minerals, will improve the mechanical properties of the spun filament.

\section{Acknowledgements}

The research was part-funded by the Engineering and Physical Sciences Research Council (EPSTC) UK (Grant Number EP/L016389/1). We would also like to thank Prof. Professor Kristiina Oksman and Dr Linn Berglund - Division of Materials Science, Luleå University of Technology, Sweden - for help on the preparation of the cellulose nanofibres. The paper sludge was processed into CNF using equipment funded by Bio4Energy Swedish strategic research program and Luleå University of Technology, Sweden.

\section{Author contributions}

The author contributions to the paper was shared equally between C.A and C.Z, who carried out the laboratory work on the preparation of the CNF from paper sludge, and the dissolution 
and spinning of fibres. The analysis results, and the manuscript were reviewed by M.J. and S.J.E. R.M.R. provided support on the calculation of the filament orientation parameters.

\section{Graphical Abstract}

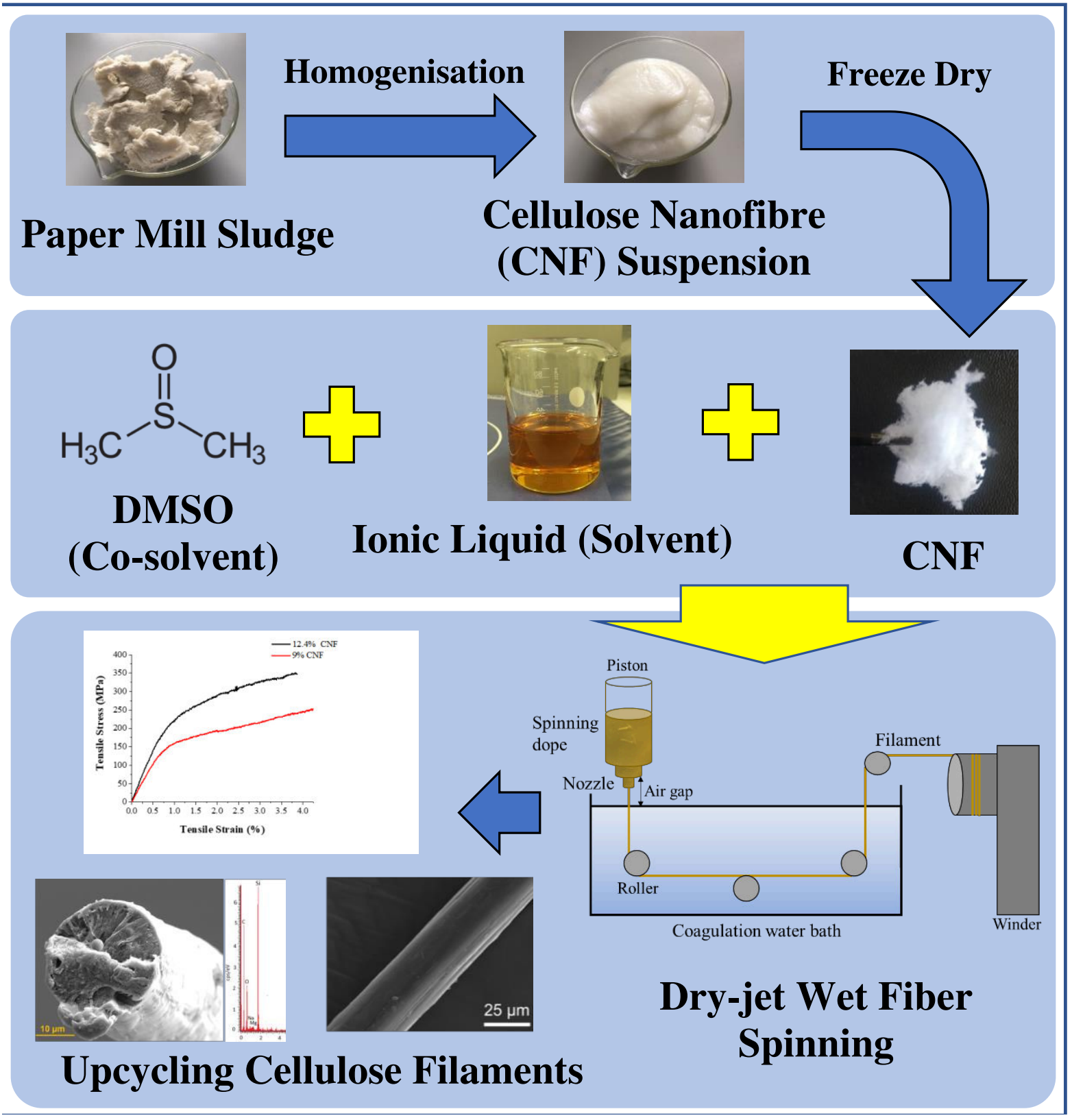




\section{References}

Adu, C., Berglund, L., Oksman, K., Eichhorn, S.J., Jolly, M., Zhu, C., 2018. Properties of cellulose nanofibre networks prepared from never-dried and dried paper mill sludge. J. Clean. Prod. 197, 765-771. https://doi.org/10.1016/j.jclepro.2018.06.263

Anugwom, I., Eta, V., Virtanen, P., Mäki-Arvela, P., Hedenström, M., Hummel, M., Sixta, H., Mikkola, J.P., 2014. Switchable ionic liquids as delignification solvents for lignocellulosic materials. ChemSusChem 7, 1170-1176. https://doi.org/10.1002/cssc.201300773

Björquist, S., Aronsson, J., Henriksson, G., Persson, A., 2018. Textile qualities of regenerated cellulose fibers from cotton waste pulp. Text. Res. J. 88, 2485-2492. https://doi.org/10.1177/0040517517723021

Chen, X., Burger, C., Fang, D., Ruan, D., Zhang, L., Hsiao, B.S., Chu, B., 2006. X-ray studies of regenerated cellulose fibers wet spun from cotton linter pulp in $\mathrm{NaOH} /$ thiourea aqueous solutions. Polymer (Guildf). 47, 2839-2848. https://doi.org/10.1016/j.polymer.2006.02.044

Clemons, C., 2016. Nanocellulose in Spun Continuous Fibers: A Review and Future Outlook. J. Renew. Mater. 4, 327-339. https://doi.org/10.7569/JRM.2016.634112

Confederation of paper industries, 2014. Code of Good Practice For Landspreading Paper Mill Sludges. Swindon.

Cox, P, W., Merz, H, E., 1958. Correlation of Dynamic and Steady flow Viscosities. Polymer (Guildf). 28, 619-622.

Eichhorn, S.J., Sirichaisit, J., Young, R.J., 2001. Deformation mechanisms in cellulose fibres , paper and wood 6, 3129-3135.

Eichhorn, S.J., Young, R.J., Davies, R.J., Riekel, C., 2003. Characterisation of the microstructure and deformation of high modulus cellulose fibres. Polymer (Guildf). 44, 5901-5908. https://doi.org/10.1016/S0032-3861(03)00540-8

Freitas, A., Mathews, R., 2017. Viscose fibres production - An assessment of sustainability 
issues [WWW Document]. Water Footpr. Netw. URL

https://waterfootprint.org/media/downloads/Viscose_fibres_Sustainability.pdf (accessed 12.2.18).

French, A.D., 2014. Idealized powder diffraction patterns for cellulose polymorphs. Cellulose 21, 885-896. https://doi.org/10.1007/s10570-013-0030-4

Ghasemi, S., Tajvidi, M., Bousfield, D.W., Gardner, D.J., Gramlich, W.M., 2017. Dry-spun neat cellulose nanofibril filaments: Influence of drying temperature and nanofibril structure on filament properties. Polymers (Basel). 9, 1-13. https://doi.org/10.3390/polym9090392

Haule, L. V., Carr, C.M., Rigout, M., 2016. Preparation and physical properties of regenerated cellulose fibres from cotton waste garments. J. Clean. Prod. 112, 44454451. https://doi.org/10.1016/j.jclepro.2015.08.086

Haward, S.J., Sharma, V., Butts, C.P., McKinley, G.H., Rahatekar, S.S., 2012. Shear and extensional rheology of cellulose/ionic liquid solutions. Biomacromolecules 13, 16881699. https://doi.org/10.1021/bm300407q

Hooshmand, S., Aitomäki, Y., Norberg, N., Mathew, A.P., Oksman, K., 2015. Dry-Spun Single-Filament Fibres Comprising Solely Cellulose Nanofibres from Bioresidue. ACS Appl. Mater. Interfaces 7, 13022-13028. https://doi.org/10.1021/acsami.5b03091

Isik, M., Sardon, H., Mecerreyes, D., 2014. Ionic liquids and cellulose: Dissolution, chemical modification and preparation of new cellulosic materials. Int. J. Mol. Sci. 15, 1192211940. https://doi.org/10.3390/ijms150711922

Lê, H.Q., Sixta, H., Hummel, M., 2019. Ionic liquids and gamma-valerolactone as case studies for green solvents in the deconstruction and refining of biomass. Curr. Opin. Green Sustain. Chem. 18, 20-24. https://doi.org/10.1016/j.cogsc.2018.11.009

Li, H., Legere, S., He, Z., Zhang, H., Li, J., Yang, B., Zhang, S., Zhang, L., Zheng, L., Ni, Y., 2018. Methods to increase the reactivity of dissolving pulp in the viscose rayon production process: a review. Cellulose 25, 3733-3753. https://doi.org/10.1007/s10570018-1840-1

Likon, M., Trebše, P., 2005. Recent Advances in Paper Mill Sludge Management. Ind. Waste 73-90. https://doi.org/10.5772/2293

Liu, H., Sale, K.L., Holmes, B.M., Simmons, B.A., Singh, S., 2010. Understanding the interactions of cellulose with ILs: MD study. J. Phys. Chem. B 114, 4293-4301.

Lundahl, M.J., Klar, V., Wang, L., Ago, M., Rojas, O.J., 2017. Spinning of cellulose nanofibrils into filaments: A review. Ind. Eng. Chem. Res. 56, 8-19. 
https://doi.org/10.1021/acs.iecr.6b04010

Ma, Y., Hummel, M., Määttänen, M., Särkilahti, A., Harlin, A., Sixta, H., 2016a. Upcycling of waste paper and cardboard to textiles. Green Chem. 18, 858-866. https://doi.org/10.1039/C5GC01679G

Ma, Y., Hummel, M., Määttänen, M., Särkilahti, A., Harlin, A., Sixta, H., 2016b. Upcycling of waste paper and cardboard to textiles. Green Chem. 18, 858-866. https://doi.org/10.1039/C5GC01679G

Manian, A.P., Pham, T., Bechtold, T., 2018. Regenerated cellulosic fibres, in: Bunsel, A.R. (Ed.), Handbook of Properties of Textile and Technical Fibres (Second Edition). Woodhead Publishing Limited, Swaston, Cambridge, pp. 329-343.

Monte, M.C., Fuente, E., Blanco, A., Negro, C., 2009. Waste management from pulp and paper production in the European Union. Waste Manag. 29, 293-308. https://doi.org/10.1016/j.wasman.2008.02.002

Northolt, M.G., 1980. Tensile deformation of poly(p-phenylene terephthalamide) fibres, an experimental and theoretical analysis. Polym. (United Kingdom) 21, 1199-1204. https://doi.org/10.1016/0032-3861(80)90088-9

Northolt, M.G., Baltussen, J.J.M., 2002. The Tensile and Compressive Deformation of Polymer and. Polym. Carbon Fibres 83, 508-538. https://doi.org/10.1002/app.22

Northolt, M.G., van Aartsen, J.J., 1977. Chain orientation distribution and elastic properties of poly (p-phenylene terephthalamide), a "rigid rod" polymer. J. Polym. Sci. Polym. Symp. 58, 283-296. https://doi.org/10.1002/polc.5070580120

Qin, J.-J., Gu, J., Chung, T.-S., 2001. Effect of wet and dry-jet wet spinning on the shearinduced orientation during the formation of ultrafiltration hollow fibre membranes.

Radhakrishnan, S., 2014. Roadmap to Sustainable Textiles and Clothing. https://doi.org/10.1007/978-981-287-065-0

Remsing, R.C., Hernandez, G., Swatloski, R.P., Massefski, W.W., Rogers, R.D., Moyna, G., 2008. Solvation of carbohydrates in N,N'-dialkylimidazolium ionic liquids: A multinuclear NMR spectroscopy study. J. Phys. Chem. B 112, 11071-11078. https://doi.org/10.1021/jp8042895

Rosenau, T., Potthast, A., Sixta, H., Kosma, P., 2001. The chemistry of side reactions and byproduct formation in the system NMMO/cellulose (Lyocell process). Prog. Polym. Sci. 26, 1763-1837. https://doi.org/10.1016/S0079-6700(01)00023-5

Schramm, G., 1998. A Practical Approach to Rheology and Rheometry.

Segal, L., Creely, J.J., Conrad, M., Martin, A.E., 1958. An Empirical Method for Estimating 
the Degree of Crystallinity of Native Cellulose Using the X-Ray Diffractometer. Text. Res. J. 786-794.

Senthil Kumar, P., Suganya, S., 2017. Introduction to sustainable fibres and textiles, Sustainable Fibres and Textiles. Elsevier Ltd. https://doi.org/10.1016/B978-0-08102041-8.00001-9

Shabbir, M., Mohammad, F., 2017. Sustainable production of regenerated cellulosic fibres, Sustainable Fibres and Textiles. Elsevier Ltd. https://doi.org/10.1016/B978-0-08102041-8.00007-X

Sieja, K., von Mach-Szczypiński, Jarosław, von Mach-Szczypiński, Joanna, 2018. Health effect of chronic exposure to carbon disulfide $\left(\mathrm{CS}_{2}\right)$ on women employed in viscose industry. Med. Pr. 69, 329-335. https://doi.org/10.13075/mp.5893.00600

Swatloski, R.P., Spear, S.K., Holbrey, J.D., Rogers, R.D., 2002. Dissolution of cellulose with ionic liquids. J. Am. Chem. Soc. 124, 4974-4975. https://doi.org/ja025790m [pii]

Tan, X., Wang, F., Bi, Y., Su, Y., Li, Y., He, J., Yi, P., Yan, J., De Bacquer, D., Braeckman, L., Vanhoorne, M., 2001. The cross-sectional study of the health effects of occupational exposure to carbon disulfide in a Chinese viscose plant. Environ. Toxicol. 16, 377-382. https://doi.org/10.1002/tox.1046

Textile Exchange, 2019. Preferred Fiber \& Materials Market Report 2019.

Wang, Z.G., Kuang, Q.L., Zhao, J.C., Niu, Y.H., Zhang, J., 2008. Celluloses in an ionic liquid: the rheological properties of the solutions spanning the dilute and semidilute regimes. J. Phys. Chem. B 112, 10234-10240. https://doi.org/10.1021/jp804167n

Wendler, F., Todi, L.N., Meister, F., 2012. Thermostability of imidazolium ionic liquids as direct solvents for cellulose. Thermochim. Acta 528, 76-84.

https://doi.org/10.1016/j.tca.2011.11.015

Wilkes, A.., 2001. The viscose process, in: Woodings, C. (Ed.), Regenerated Cellulose Fibres. Woodhead Publishing Limited, Cambridge, UK, pp. 37-57.

Yu, M., Wan, J., 2017. Environmental Friendly Development of Regenerated Cellulose Fibre Production. DEStech Trans. Eng. Technol. Res. 760-765.

https://doi.org/10.12783/dtetr/apetc2017/11079

Yuan, X., Cheng, G., 2015. From cellulose fibrils to single chains: Understanding cellulose dissolution in ionic liquids. Phys. Chem. Chem. Phys. 17, 31592-31607. https://doi.org/10.1039/c5cp05744b

Zajáros, A., Szita, K., Matolcsy, K., Horváth, D., 2018. Life cycle sustainability assessment of DMSO solvent recovery from hazardous waste water. Period. Polytech. Chem. Eng. 
62, 305-309. https://doi.org/10.3311/PPch.11097

Zhu, C., Koutsomitopoulou, A.F., Eichhorn, S.J., van Duijneveldt, J.S., Richardson, R.M., Nigmatullin, R., Potter, K.D., 2018. High Stiffness Cellulose Fibres from Low Molecular Weight Microcrystalline Cellulose Solutions Using DMSO as Co-Solvent with Ionic Liquid. Macromol. Mater. Eng. 303, 1-6. https://doi.org/10.1002/mame.201800029

Zhu, C., Richardson, R.M., Potter, K.D., Koutsomitopoulou, A.F., van Duijneveldt, J.S., Vincent, S.R., Wanasekara, N.D., Eichhorn, S.J., Rahatekar, S.S., 2016. High Modulus Regenerated Cellulose Fibres Spun from a Low Molecular Weight Microcrystalline Cellulose Solution. ACS Sustain. Chem. Eng. 4, 4545-4553. https://doi.org/10.1021/acssuschemeng.6b00555 


\section{Supplementary information}

Continuous and Sustainable Cellulose Filaments from Ionic Liquid Dissolved Paper Sludge Nanofibres

Cynthia Adu ${ }^{\mathrm{a}}$, Chenchen Zhu ${ }^{\mathrm{b}}$, Mark Jolly ${ }^{\mathrm{a}}$, Robert M. Richardson ${ }^{\mathrm{c}}$, Stephen J Eichhorn ${ }^{\mathrm{b}}$

${ }^{a}$ Sustainable Manufacturing Systems Centre, Cranfield University, Cranfield, Bedfordshire MK43 0AL, United Kingdom

${ }^{b}$ Bristol Composites Institute, School of Civil, Aerospace, and Mechanical Engineering, University of Bristol, Bristol BS8 1TR, United Kingdom

${ }^{\mathrm{c}} \mathrm{HH}$ Wills Physics Laboratory, Physics Department, University of Bristol, Tyndall Avenue, Bristol BS8 1TL, U.K.

\section{Corresponding Authors}

*E-mail: s.j.eichhorn@bristol.ac.uk 
Table S1: Mechanical Properties of Spun Filaments 9\% CNF

\begin{tabular}{|l|l|l|l|l|l|}
\hline RECORD & Diameter & MEAN AREA & $\begin{array}{l}\text { Youngs } \\
\text { modulus }\end{array}$ & STRAIN & $\begin{array}{l}\text { TENSILE } \\
\text { STRENGTH }\end{array}$ \\
\hline & $\mu \mathrm{m}$ & $\mu \mathrm{m}^{2}$ & $\mathrm{GPa}$ & $\%$ & MPa \\
\hline 1 & 33.1 & 819 & 21.7 & 5.6 & 280.0 \\
\hline 2 & 34.5 & 920.7 & 19.9 & 5.6 & 233.0 \\
\hline 3 & 30.9 & 734.7 & 18.8 & 2.4 & 186.3 \\
\hline 4 & 29.6 & 670.3 & 20.9 & 2.5 & 187.0 \\
\hline 5 & 29.7 & 679.9 & 19.6 & 3.6 & 185.0 \\
\hline 6 & 29.7 & 658.6 & 18.3 & 4.3 & 231.8 \\
\hline Ave & $\mathbf{3 1 . 3}$ & $\mathbf{7 4 7 . 2}$ & $\mathbf{1 9 . 9}$ & $\mathbf{4 . 0}$ & $\mathbf{2 2 3 . 4}$ \\
\hline SD & $\mathbf{2 . 1}$ & $\mathbf{1 0 3 . 6}$ & $\mathbf{1 . 3}$ & $\mathbf{1 . 4}$ & $\mathbf{3 9 . 3}$ \\
\hline
\end{tabular}

Table S2: Mechanical Properties of Spun Filaments 12.4\% CNF

\begin{tabular}{|l|l|l|l|l|l|}
\hline RECORD & Diameter & MEAN AREA & $\begin{array}{l}\text { Youngs } \\
\text { modulus }\end{array}$ & STRAIN & $\begin{array}{l}\text { TENSILE } \\
\text { STRENGTH }\end{array}$ \\
\hline Sample no & $\mu \mathrm{m}$ & $\mu \mathrm{m}^{2}$ & $\mathrm{GPa}$ & $\%$ & MPa \\
\hline Sample 1 & 24.1 & 381.5 & 26.5 & 3.2 & 315.1 \\
\hline Sample 2 & 24.1 & 453.2 & 25.5 & 4.9 & 325.0 \\
\hline Sample 3 & 23.4 & 428.8 & 27.5 & 2.5 & 290.4 \\
\hline Sample 4 & 25.9 & 504.3 & 25.0 & 1.5 & 233.0 \\
\hline Sample 5 & 24.5 & 466.6 & 29.2 & 3.9 & 347.0 \\
\hline Sample 6 & 25.0 & 480.2 & 26.7 & 1.7 & 253.0 \\
\hline Sample 1a & 23.6 & 436.0 & 25.1 & 1.9 & 252.1 \\
\hline Sample 2a & 25.7 & 520.4 & 24.1 & 2.0 & 239.4 \\
\hline Sample 3a & 23.4 & 435.3 & 25.5 & 1.9 & 285.0 \\
\hline Sample 4a & 25.4 & 497.8 & 24.2 & 1.4 & 251.0 \\
\hline Sample 5a & 26.9 & 548.5 & 27.9 & 3.0 & 334.1 \\
\hline Sample 6a & 24.3 & 459.0 & 23.2 & 1.9 & 262.2 \\
\hline Ave & $\mathbf{2 4 . 7}$ & $\mathbf{4 6 7 . 6}$ & $\mathbf{2 5 . 9}$ & $\mathbf{2 . 5}$ & $\mathbf{2 8 2 . 3}$ \\
\hline SD & $\mathbf{1 . 1}$ & $\mathbf{4 5 . 7}$ & $\mathbf{1 . 7}$ & $\mathbf{1 . 1}$ & $\mathbf{3 9 . 6}$ \\
\hline & & & & & \\
\hline
\end{tabular}

Figure S1: Deconvoluted WAXD pattern of $9 \%$ and $12.4 \% \mathrm{CNF}$
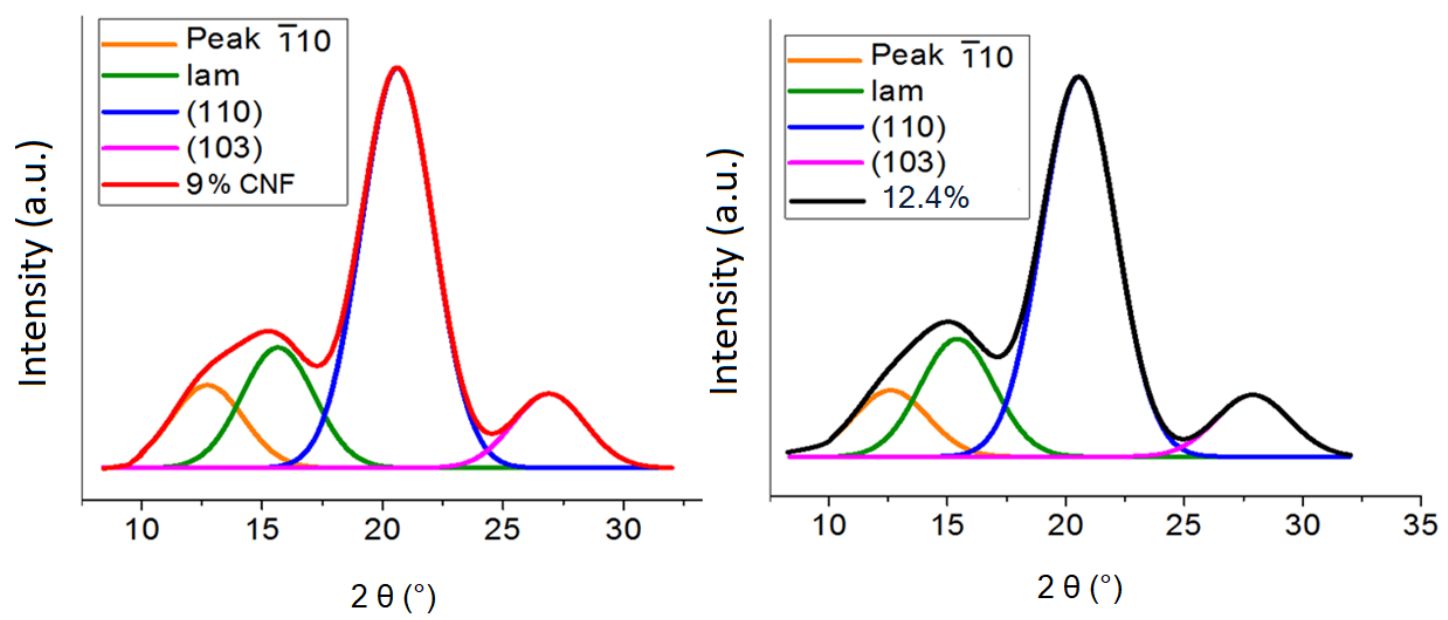
Figure S2: WAXD azimuthal scanning data used to calculate FWHM

The FWHM was calculated from the azimuthal scanning data of the (110). The FWHM for $9 \%$ and $12.4 \%$ was $29.22^{\circ}$ and $27.25^{\circ}$ respectively.

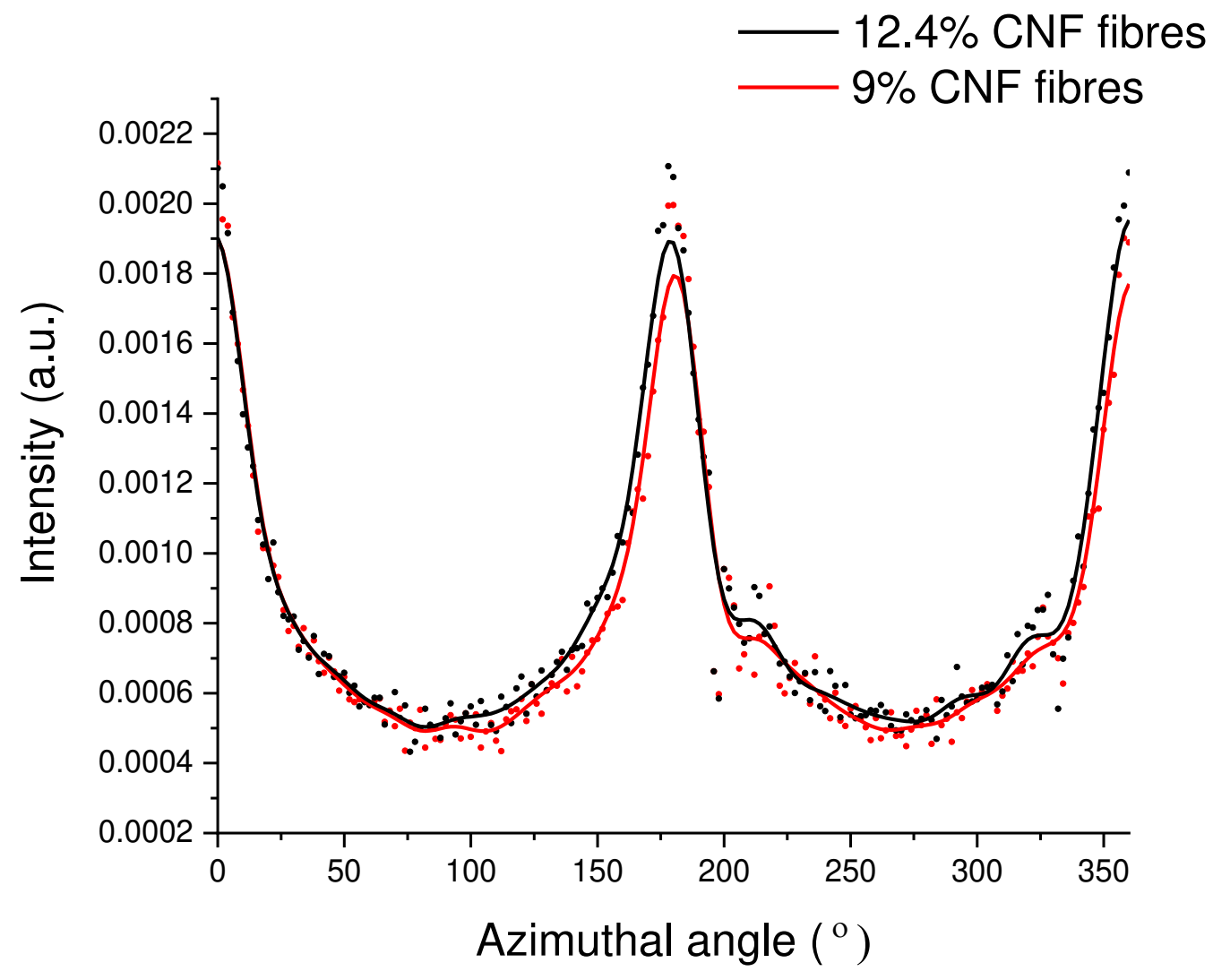

Table S3: Mechanical Properties of Spun Filaments 12.4\% CNF

\begin{tabular}{|c|c|c|c|c|c|}
\hline Material & $\begin{array}{l}\text { Spinning } \\
\text { method }\end{array}$ & $\begin{array}{l}\text { Diameter } \\
(\mu \mathrm{m})\end{array}$ & $\begin{array}{l}\text { Tensile } \\
\text { strength } \\
\text { (MPa) }\end{array}$ & $\begin{array}{l}\text { Modulus } \\
\text { (GPa) }\end{array}$ & Reference \\
\hline $9 \%$ paper sludge & $\begin{array}{l}\text { Dry-Jet } \\
\text { wet }\end{array}$ & 31 & 223 & 19 & This work \\
\hline $12.4 \%$ paper sludge & $\begin{array}{l}\text { Dry-Jet } \\
\text { wet }\end{array}$ & 25 & 282 & 26 & This work \\
\hline $\begin{array}{l}\text { CNF } \\
\text {-Banana rachis 6.5- } \\
288\end{array}$ & Dry & 210 & 222 & 12.6 & $\begin{array}{l}\text { (Hooshmand et } \\
\text { al., 2015) }\end{array}$ \\
\hline $\begin{array}{l}\text { CNF } \\
\text {-Kraft pulp }\end{array}$ & Dry & 180 & 120 & 6 & $\begin{array}{l}\text { (Ghasemi et } \\
\text { al., 2017) }\end{array}$ \\
\hline $\begin{array}{l}\text { MCC } \\
-12.4 \mathrm{wt} \% \\
-15.2 \mathrm{wt} \% \\
-18.0 \mathrm{wt} \%\end{array}$ & $\begin{array}{l}\text { Dry-Jet } \\
\text { wet }\end{array}$ & $\begin{array}{l}22 \\
23 \\
20\end{array}$ & $\begin{array}{l}215 \\
226 \\
304 \\
\end{array}$ & $\begin{array}{l}14.8 \\
15.7 \\
22.4 \\
\end{array}$ & $\begin{array}{l}\text { (Zhu et al., } \\
\text { 2016) }\end{array}$ \\
\hline $\begin{array}{l}\text { MCC } \\
-18.0 \mathrm{wt} \% \\
-20.8 \mathrm{wt} \% \\
\end{array}$ & $\begin{array}{l}\text { Dry-Jet } \\
\text { wet }\end{array}$ & $\begin{array}{l}22.4 \\
27.8\end{array}$ & $\begin{array}{l}304 \\
373 \\
\end{array}$ & $\begin{array}{l}20 \\
28\end{array}$ & $\begin{array}{l}\text { (Zhu et al., } \\
\text { 2018) }\end{array}$ \\
\hline
\end{tabular}




\begin{tabular}{|c|c|c|c|c|c|}
\hline$-23.6 \mathrm{wt} \%$ & & 41.2 & 555 & 18 & \\
\hline $\begin{array}{l}\text { CNF } \\
\text {-Tempo wood } \\
\text {-Tunicate }\end{array}$ & Wet & $\begin{array}{l}60 \\
60\end{array}$ & $\begin{array}{l}321 \\
406\end{array}$ & $\begin{array}{l}23.6 \\
18.9\end{array}$ & $\begin{array}{l}\text { (Iwamoto et } \\
\text { al., 2011) }\end{array}$ \\
\hline $\begin{array}{l}\text { Dissolving pulp } \\
-([\mathrm{DBNH}]) 13 \mathrm{wt} \%\end{array}$ & $\begin{array}{l}\text { Dry-Jet } \\
\text { wet }\end{array}$ & $\begin{array}{l}\text { Not } \\
\text { reported }\end{array}$ & 552 & 23.2 & $\begin{array}{l}\text { (Hauru et al., } \\
\text { 2014) }\end{array}$ \\
\hline $\begin{array}{l}\text { Paper } \\
\text {-P1 (ash removal) } \\
\text {-P2 } \\
\text { Cardboard } \\
\text {-B1 } \\
\text {-B2 } \\
- \text { B3 } \\
\text {-B4 } \\
\text {-B5 }\end{array}$ & $\begin{array}{l}\text { Dry-Jet } \\
\text { wet }\end{array}$ & $\begin{array}{l}\text { Not } \\
\text { reported }\end{array}$ & $\begin{array}{l}563.7 \\
662.0 \\
\\
\\
13.2 \\
665.6 \\
770.7 \\
711.3 \\
696.7 \\
\end{array}$ & $\begin{array}{l}21.73 \\
24.46 \\
\\
7.1 \\
23.4 \\
27.1 \\
23.6 \\
25.4 \\
\end{array}$ & $\begin{array}{l}\text { (Ma et al., } \\
\text { 2016a) }\end{array}$ \\
\hline
\end{tabular}


2020-10-03

\title{
Continuous and sustainable cellulose filaments from ionic liquid dissolved paper sludge nanofibres
}

\author{
Adu, Cynthia
}

Elsevier

Adu C, Zhu C, Jolly M, et al., (2021) Continuous and sustainable cellulose filaments from ionic liquid dissolved paper sludge nanofibres. Journal of Cleaner Production, Volume 280 Pt.2, January 2021, Article number 124503

https://doi.org/10.1016/j.jclepro.2020.124503

Downloaded from Cranfield Library Services E-Repository 